\title{
BMJ Open Patient satisfaction and non-UK educated nurses: a cross-sectional observational study of English National Health Service Hospitals
}

\author{
Hayley D Germack, ${ }^{1}$ Peter Griffiths, ${ }^{2}$ Douglas M Sloane, ${ }^{1}$ Anne Marie Rafferty, ${ }^{3}$ \\ Jane $\mathrm{E}$ Ball, ${ }^{2}$ Linda $\mathrm{H}$ Aiken ${ }^{1}$
}

To cite: Germack HD, Griffiths P, Sloane DM, et al. Patient satisfaction and nonUK educated nurses: a crosssectional observational study of English National Health Service Hospitals. BMJ Open 2015;5:e009483.

doi:10.1136/bmjopen-2015009483

- Prepublication history for this paper is available online. To view these files please visit the journal online (http://dx.doi.org/10.1136/ bmjopen-2015-009483)

Received 28 July 2015 Revised 27 October 2015 Accepted 3 November 2015

\section{CrossMark}

${ }^{1}$ Center for Health Outcomes and Policy Research, University of Pennsylvania School of Nursing, Philadelphia, Pennsylvania USA

${ }^{2}$ National Institute for Health Research Collaboration for Applied Leadership in Health Research Wessex, University of Southampton,

Southampton, UK

${ }^{3}$ National Nursing Research Unit, Florence Nightingale Faculty of Nursing and Midwifery, King's College London, London, UK

Correspondence to Professor Linda H Aiken; laiken@nursing.upenn.edu

\section{ABSTRACT}

Objectives: To examine whether patient satisfaction with nursing care in National Health Service (NHS) hospitals in England is associated with the proportion of non-UK educated nurses providing care.

Design: Cross-sectional analysis using data from the 2010 NHS Adult Inpatient Survey merged with data from nurse and hospital administrator surveys. Logistic regression models with corrections for clustering were used to determine whether the proportions of non-UK educated nurses were significantly related to patient satisfaction before and after taking account of other hospital, nursing and patient characteristics.

Setting: 31 English NHS trusts.

Participants: 12506 patients 16 years of age and older with at least one overnight stay that completed a satisfaction survey; 2962 bedside care nurses who completed a nurse survey; and 31 NHS trusts.

Main outcome measure: Patient satisfaction.

Results: The percentage of non-UK educated nurses providing bedside hospital care, which ranged from $1 \%$ to $52 \%$ of nurses, was significantly associated with patient satisfaction. After controlling for potential confounding factors, each 10-point increase in the percentage of non-UK educated nurses diminished the odds of patients reporting good or excellent care by $12 \%(\mathrm{OR}=0.88)$, and decreased the odds of patients agreeing that they always had confidence and trust in nurses by $13 \%(\mathrm{OR}=0.87)$. Other indicators of patient satisfaction also revealed lower satisfaction in hospitals with higher percentages of non-UK educated nurses.

Conclusions: Use of non-UK educated nurses in English NHS hospitals is associated with lower patient satisfaction. Importing nurses from abroad to substitute for domestically educated nurses may negatively impact quality of care.

\section{INTRODUCTION}

The WHO in 2000 included in its definition of quality of healthcare patients' experiences and satisfaction with their healthcare. ${ }^{1}$ About the same time, the prestigious Institute of Medicine in the USA concluded that

\section{Strengths and limitations of this study}

- This is the first quantitative study to determine the association between employment of nurses trained abroad and patient satisfaction in a representative national sample of hospitals in England.

- Unique data previously unavailable enable a rigorous analysis of alternative explanations for lower patient satisfaction associated with high employment of nurses educated abroad.

- The findings hold important policy implications for workforce planning.

- The study uses cross-sectional data, and while a number of alternative explanations are considered in our models, we cannot rule out the possibility that omitted variables may contribute to associations found.

improving patient experiences with their care was one of six priority areas for improving healthcare quality. ${ }^{2}$ Subsequently, a number of countries, including England, began to monitor patient satisfaction as an indicator of quality of care through ongoing surveys of patients following hospital discharge. ${ }^{3}$ England's National Health Service (NHS), noting that health services should be shaped by what matters most to patients and the public, sponsors the NHS patient survey programmes to enable the independent Care Quality Commission to monitor quality of healthcare. ${ }^{4}$

Maintaining acceptable quality of healthcare is increasingly challenging under current circumstances of slow economic growth and rising healthcare expenditures. Two recent high profile reports on quality of care in English NHS hospitals called attention to egregious lapses in care quality in one hospital ${ }^{5}$ and persistently high mortality in 14 NHS hospital trusts. 6 Both reports 
made an explicit link between poor quality of care and inadequate nurse resources. Nurses have been caught in the 'quality storm' with some blaming nurses for having uncaring attitudes while researchers produce evidence that the problem is the under-resourcing of nurses in NHS hospitals. ${ }^{78}$

Shortages of nurses at the hospital bedside result both from an inadequate national supply of nurses as well as too few budgeted positions for nurses in hospitals. In the future, England will need to replace large numbers of nurses reaching retirement age. Retirements, coupled with a growing demand for healthcare by an ageing population and increasing prevalence of chronic health conditions create the strong possibility of impending shortages of nurses nationally and locally without policy intervention. Thus, the timing is right for a thorough examination of strategies for increasing nurse supply.

For decades, the UK has resorted to recruiting nurses from other countries when faced with shortages at home. ${ }^{9}{ }^{10}$ At the peak of UK international nurse recruitment in 2001, more than half of new nurses on the UK register were educated abroad. ${ }^{11}$ The UK was criticised for recruiting nurses from countries suffering from their own nursing shortages, including a highly publicised plea from Nelson Mandela for the NHS to ban recruitment from South Africa. ${ }^{12}$

Following recent national concern about low hospital nurse staffing levels putting patients at risk, there has been an upturn in hospital recruitment of nurses abroad with NHS trusts reportedly spending at least $£ 2.5$ million in the past 2 years recruiting nurses from Portugal, Spain and Romania in Europe, as well as from the Philippines and India. ${ }^{13}$ A recent study examining the association between proportion of non-US educated nurses practising in US hospitals and 30-day mortality following common surgical procedures found significantly higher risk-adjusted mortality in hospitals that employ higher proportions of non-US educated nurses, after controls for potentially confounding factors. ${ }^{14}$ Surprisingly, little research has been undertaken in the UK, considering its long-term dependence on nurses educated abroad, to determine whether there are quality of care considerations in importing nurses trained in other countries to fill gaps in the UK's national nurse supply.

There is growing evidence suggesting an association between nursing and patient satisfaction. Nursing has been found to be a major factor associated with patient satisfaction. ${ }^{15}{ }^{16}$ The European Union (EU)-funded Nurse Forecasting in Europe (RN4CAST) study found that patients cared for in hospitals with better nurse staffing and good nurse work environments were significantly more likely to rate their hospitals highly, to be willing to recommend their hospitals, and to be satisfied with nursing care. ${ }^{17}$ The current study explores whether employment of nurses educated outside the UK is associated with patient satisfaction in NHS hospitals in England.
METHODS

\section{Data sources and samples}

We studied patient reports of satisfaction in 31 NHS trusts in England (the largest of the four nations comprising the UK with approximately $85 \%$ of the total population) using data from 2010 from three sources: (1) the NHS Adult Inpatient Survey, ${ }^{18}$ which asked patients about the overall quality of care they received in hospitals as well as their perceptions of nurses and other staff; (2) the RN4CAST England Nurse Survey, which asked nurses (among other things) about their workloads, the work environment in their hospital and where they received their nursing education; ${ }^{19}$ and (3) the RN4CAST Organisational Profile Survey in England that requested information from hospital administrators about selected organisational characteristics of their hospitals, including hospital size, teaching status and types of available technology. ${ }^{19}$

\section{Hospital trusts}

Thirty-one NHS trusts representing 46 hospitals were selected for participation from a random sample of NHS trusts in England stratified by geographic area, size and teaching status. Hospital administrators from the 31 trusts provided information on the size, teaching status, technology status and location of the trusts, which we use to describe the different trusts and control for in our analyses of the effects of non-UK educated nurses on patient satisfaction. Trusts were categorised as large if they had more than 750 beds, which was the average (mean) number of beds across all trusts in the sample. Technology status was defined as high if the trust had the capacity to perform open heart surgery or organ transplantation. Teaching status was determined by whether the trust was affiliated to a medical school and provided training to undergraduate student doctors. Location referred to whether the trust was urban or rural and whether it was inside or outside of London. Other hospital characteristics were measured by aggregating responses from the nurses surveyed, as described below.

\section{Nurses}

Bedside care professional nurses were informants via surveys about nurse staffing and work environments in participating hospitals. All professional nurses caring for patients on general medical and surgical units in the 31 trusts (up to a maximum 10 units per hospital) were invited to complete a survey. ${ }^{19}$ Surveys were received from 2962 nurses out of 7741 nurses, a response rate of $38 \%$. Our nurse sample consists of an average of 96 nurses per trust (with a range of 42 nurses to 203 nurses per trust). Previous research using the same nurse survey instrument has demonstrated that as few as 10 nurses per hospital yields reliable and valid hospital-level measures of the variables under study here. Additionally, comprehensive interviews with nurse non-respondents document no response bias with regard to the hospitallevel measures under study here. ${ }^{20}$ 
Non-UK educated nurses were self-identified from the nurse survey as having received their basic professional nursing education in a country other than the UK. The 476 non-UK educated nurses comprised $16 \%$ of respondents. The proportion of non-UK nurses varied by trust from $1 \%$ to $52 \%$ of all nurses.

Responses from individual nurses were aggregated to create trust-level measures of the nurse work environment and nurse staffing. The work environment was measured using the Practice Environment Scale of the Nursing Work Index (PES-NWI), an extensively validated instrument ${ }^{21-24}$ endorsed by the National Quality Forum. ${ }^{25}{ }^{26}$ Nurses were presented with a battery of items on the survey and asked to indicate their level of agreement (using a four-point scale ranging from strongly agree to strongly disagree) that certain organisational features were present in their jobs. Their responses were then used to produce five PES-NWI subscales: nurse involvement in hospital affairs, nursing foundations for high-quality patient care, nurse manager leadership, staffing and resource adequacy, and nursephysician relationships. A summary measure was calculated for each hospital representing the sum of subscales above the median, after individual nurse responses were averaged in each hospital. Hospitals in which nurses rated four or five subscales above the median were classified as hospitals with better work environments, those with two or three subscales above the median were classified as mixed; and hospitals with none or one subscale above the median were classified as having poor work environments.

Nurse staffing was measured by averaging the number of patients that each nurse reported caring for on their last shift ${ }^{27}$ across all nurses in the same trust. Those who reported caring for greater than 19 patients or less than one were excluded from the sample, assuming they were not providing direct patient care. Lower patient-to-nurse ratios indicate more favourable staffing.

\section{Patients}

Our analysis includes reports from 12506 patients receiving care in the 31 participating trusts. Data were obtained from the 2010 NHS Adult Inpatient Survey. The questionnaire, administered annually, covers the spectrum of care from arrival at the hospital to discharge. Patients were eligible for the survey if they were 16 years or older, had at least one overnight stay, and were not under the care of a consultant from maternity or psychiatric specialties. The NHS received responses from over 69000 patients, a response rate of $52 \%$ of which 12506 patients were discharged from hospitals in the trusts included in our study. There were on average 403 patient surveys returned from each sampled trust. Patient satisfaction with care was measured by seven survey items, including an overall patient rating of care, whether the patient wanted to complain about care, whether the patient was treated with respect and dignity, whether explanations about medications were given and understandable, whether nurses answered questions clearly, whether the patient had confidence and trust in nurses providing care, and whether there were enough nurses.

Patient characteristics included as control variables in our analyses were patients' age, sex, length of stay (LOS), admission type (emergency or planned), and the presence of limiting long-term conditions, including deafness or hearing impairment, blindness or partial sightedness, illnesses (ie, cancer, HIV, diabetes, chronic heart disease or epilepsy), physical conditions, mental health conditions, and learning disabilities.

\section{Analysis strategy}

We first compared characteristics of UK and non-UK educated nurses in the sample, using $\mathrm{F}$ tests (for continuous variables) and $\chi^{2}$ tests (for categorical variables) to determine their significance, and provide information on the country in which non-UK educated nurses received their education. We examined characteristics of the patients in the sample using means and SDs for continuous variables and percentages for categorical variables. We then examined hospital trust characteristics and how they differ across trusts with low $(<5 \%)$, moderate $(5-20 \%)$ and high $(>20 \%)$ proportions of non-UK educated nurses. The $\chi^{2}$ tests were used for categorical variables to evaluate differences between the groups.

To estimate the effects of the proportion of non-UK educated nurses in the different trusts on patient reports of satisfaction, we used robust logistic regression models with Huber/White sandwich estimators to adjust the SEs for the clustering of patients within trusts. We first estimated bivariate models, which show the unadjusted main (or direct) effects of a $10 \%$ increase in the proportion of non-UK educated nurses on each of the patient outcome measures, without additional controls. We then estimated adjusted models which show the main effect of a $10 \%$ increase in the proportion of non-UK educated nurses after controlling for trust characteristics (size, technology status, nurse staffing and the quality of the practice environment) and patient characteristics (age, sex, LOS, admission type, ward and the presence of limiting long-term conditions). Analyses were conducted using STATA V.13.1. ${ }^{28}$

\section{RESULTS}

\section{Descriptive statistics}

Demographic characteristics of the 2962 nurses in this study are shown in table 1 , comparing non-UK educated nurses $(n=476)$ and UK educated nurses $(n=2486)$. While the average age of the nurses was similar in both groups, at just under 40 years, non-UK educated nurses were more likely to be male ( $12 \%$ vs $7 \%)$ and had more years of nursing experience ( $16.6 \pm 7.4$ vs $13.4 \pm 11$ years). The primary countries in which the non-UK educated nurses received their nursing education included the Philippines (30\%), India (24\%) and various countries in 
Table 1 Nurse characteristics in the study hospitals $(\mathrm{N}=2962)$

\begin{tabular}{|c|c|c|c|}
\hline Nurse characteristics & $\begin{array}{l}\text { Non-UK } \\
\text { educated } \\
\text { nurses } \\
(\mathrm{N}=476)\end{array}$ & $\begin{array}{l}\text { UK } \\
\text { educated } \\
\text { nurses } \\
(\mathrm{N}=2486)\end{array}$ & p Value* \\
\hline Age (mean $\pm S D)$ & $39.3 \pm 7.8$ & $39.7 \pm 10.5$ & 0.39 \\
\hline $\begin{array}{l}\text { Years of experience } \\
\text { (mean } \pm S D)\end{array}$ & $16.6 \pm 7.4$ & $13.4 \pm 11$ & $<0.001$ \\
\hline \multicolumn{4}{|l|}{$\operatorname{Sex}(N(\%))$} \\
\hline Male & $59(12)$ & $173(7)$ & $<0.001$ \\
\hline Female & $416(88)$ & $2296(93)$ & \\
\hline \multicolumn{4}{|c|}{ Country of education (N (\%)) } \\
\hline Philippines & $145(30)$ & & \\
\hline India & $113(24)$ & & \\
\hline Africa (all countries) & 89 (19) & & \\
\hline Europe (non-UK) & $35(7)$ & & \\
\hline Other Asian & $15(3)$ & & \\
\hline Other Western† & $8(3)$ & & \\
\hline Otherf & $7(1)$ & & \\
\hline Missing/invalid & $64(13)$ & & \\
\hline \multicolumn{4}{|c|}{$\begin{array}{l}{ }^{*} p \text { Values are based on } \mathrm{F} \text { tests or (in the case of per cent male) } \\
\text { on the } \chi^{2} \text { test. } \\
\text { †Includes the USA, Canada, Australia and New Zealand. } \\
\text { fIncludes Saudi Arabia, Caribbean countries and South American } \\
\text { countries. }\end{array}$} \\
\hline
\end{tabular}

Africa (19\%). Some $7 \%$ of the non-UK educated nurses were from other European countries.

The average LOS for the 12506 patients in our sample was just under 6 days, though the sizable SD associated with the average LOS (over 9 days) indicates that many patients had hospitalisations of much longer duration (table 2). More than half of the patients surveyed $(52 \%)$ were over the age of 66 and just over half $(53 \%)$ were women. The majority of patients $(60 \%)$ were emergency admissions, and the largest numbers of these patients were discharged from general medical wards (23\%), general surgical wards $(19 \%)$ and trauma and orthopaedics wards (14\%). More than half of the sample reported having at least one limiting long-term condition along with the reason for their hospitalisation; $39 \%$ reported a single limiting long-term condition and $17 \%$ reported multiple conditions. Satisfactory outcomes were expressed to the 11 items indicating satisfaction with care by between $59 \%$ of the patients, who indicated that there were always enough nurses on duty, and $97 \%$ of the patients, who indicated they were always treated with respect and dignity in the hospital and always had trust and confidence in the nurses.

Overall, roughly one-third of the trusts were high technology, and roughly 4 in 10 were teaching hospitals (table 3). Twenty-six of the 31 hospital trusts were located outside of London, one-third of them had workloads involving more than eight patients per nurse, and more than one-third had poor work environments. Compared with trusts with low $(\mathrm{n}=7)$ or moderate $(n=11)$ proportions of non-UK educated nurses, those
Table 2 Patient characteristics and outcomes in the study hospitals ( $\mathrm{N}=12506)$

\begin{tabular}{|c|c|}
\hline \multicolumn{2}{|l|}{ Patient characteristics } \\
\hline Average length of stay (mean $\pm S D$ ) & $5.7 \pm 9.3$ days \\
\hline \multicolumn{2}{|l|}{ Age group $(\mathrm{N}(\%))$} \\
\hline $16-35$ & $1070(9)$ \\
\hline $36-50$ & $1742(14)$ \\
\hline $51-65$ & $3203(26)$ \\
\hline $66+$ & $6491(52)$ \\
\hline \multicolumn{2}{|l|}{$\operatorname{Sex}(N(\%))$} \\
\hline Male & $5813(47)$ \\
\hline Female & $6693(53)$ \\
\hline \multicolumn{2}{|l|}{ Type of hospitalisation (N (\%)) } \\
\hline Emergency & $7255(60)$ \\
\hline Non-emergency & $4814(40)$ \\
\hline \multicolumn{2}{|l|}{ Discharge ward (N (\%)) } \\
\hline General medicine & $2852(23)$ \\
\hline General surgery & $2321(19)$ \\
\hline Trauma and orthopaedics & $1791(14)$ \\
\hline Cardiology & $746(6)$ \\
\hline Urology & $744(6)$ \\
\hline Gynaecology & $680(5)$ \\
\hline Geriatric medicine & $539(4)$ \\
\hline All other & $2833(23)$ \\
\hline \multicolumn{2}{|l|}{ Limiting long-term conditions (N (\%))* } \\
\hline None & $5543(44)$ \\
\hline One & 4862 (39) \\
\hline Two or more & 2101 (17) \\
\hline \multicolumn{2}{|l|}{ Outcomes (satisfaction) (N (\%)) } \\
\hline $\begin{array}{l}\text { Rated care received as very good or } \\
\text { excellent }\end{array}$ & $9402(78)$ \\
\hline Did not want to complain about care & $10898(92)$ \\
\hline $\begin{array}{l}\text { Always treated with respect and dignity } \\
\text { while in the hospital }\end{array}$ & $11780(97)$ \\
\hline $\begin{array}{l}\text { A member of staff always explained the } \\
\text { purpose of medicinest }\end{array}$ & 8372 (78) \\
\hline $\begin{array}{l}\text { Nurses always provide easy to } \\
\text { understand answers }\end{array}$ & 10629 (86) \\
\hline $\begin{array}{l}\text { Always have confidence and trust in } \\
\text { nurses }\end{array}$ & $11940(97)$ \\
\hline $\begin{array}{l}\text { There were always enough nurses on } \\
\text { duty to care for the patient in the hospital }\end{array}$ & 7214 (59) \\
\hline \multicolumn{2}{|c|}{$\begin{array}{l}\text { Data were missing for no more than } 4 \% \text { or respondents on any } \\
\text { item. } \\
\text { *Limiting long-term conditions include deafness or hearing } \\
\text { impairment, blindness or partial sightedness, illnesses (ie, cancer, } \\
\text { HIV, diabetes, chronic heart disease or epilepsy), physical } \\
\text { conditions, mental health conditions and learning disabilities. } \\
\text { tQuestion only asked of patients receiving medications and who } \\
\text { indicated they sometimes needed medications explained. }\end{array}$} \\
\hline
\end{tabular}

with a high proportion $(\mathrm{n}=13)$ were significantly more likely to be located in London and have more than 750 beds. Trusts with different proportions of non-UK educated nurses did not differ significantly with respect to technology, teaching status, nurse staffing or quality of the nurse work environment.

\section{Outcomes}

The estimated effects of having greater proportions of non-UK educated nurses on patient satisfaction are 
Table 3 Characteristics of the hospital trusts ( $N=31$ ), overall and by the proportion of non-UK educated nurses (FENs)

\begin{tabular}{|c|c|c|c|c|c|}
\hline \multirow[b]{2}{*}{ Characteristic (N (\%)) } & \multirow[b]{2}{*}{$\begin{array}{l}\text { All trusts } \\
(\mathrm{N}=31)\end{array}$} & \multicolumn{3}{|c|}{ Hospital trust group-trusts with } & \multirow[b]{2}{*}{ p Value* } \\
\hline & & $\begin{array}{l}\text { High proportion } \\
\text { of FENs } \\
\text { ( } \mathrm{N}=13 \text { ) }\end{array}$ & $\begin{array}{l}\text { Middle proportion } \\
\text { of FENs } \\
(\mathrm{N}=11)\end{array}$ & $\begin{array}{l}\text { Low proportion } \\
\text { of FENs } \\
(\mathrm{N}=7)\end{array}$ & \\
\hline \multicolumn{6}{|l|}{ Technology } \\
\hline High & $11(35)$ & $6(46)$ & $4(36)$ & $1(14)$ & \multirow[t]{2}{*}{0.330} \\
\hline Low & $20(65)$ & $7(54)$ & $7(64)$ & $6(86)$ & \\
\hline \multicolumn{6}{|l|}{ Hospital size } \\
\hline Under 750 beds & $16(52)$ & $3(23)$ & $8(73)$ & $5(71)$ & \multirow{2}{*}{0.022} \\
\hline 750 beds or more & $15(48)$ & $10(77)$ & $3(27)$ & $2(29)$ & \\
\hline \multicolumn{6}{|l|}{ Teaching status } \\
\hline Teaching hospital & $13(42)$ & $7(54)$ & $3(27)$ & $3(43)$ & \multirow[t]{2}{*}{0.413} \\
\hline Non-teaching hospital & $18(58)$ & $6(46)$ & $8(73)$ & $4(57)$ & \\
\hline \multicolumn{6}{|l|}{ Location } \\
\hline London & $5(16)$ & $5(38)$ & $0(0)$ & $0(0)$ & \multirow[t]{2}{*}{0.007} \\
\hline Not London & $26(84)$ & $8(62)$ & $11(100)$ & $7(100)$ & \\
\hline \multicolumn{6}{|l|}{ Staffing } \\
\hline$<7$ patients per nurse & $6(19)$ & $4(31)$ & $2(18)$ & $0(0)$ & \multirow[t]{3}{*}{0.082} \\
\hline $7-8$ patients per nurse & $15(48)$ & $6(46)$ & $7(64)$ & $2(29)$ & \\
\hline$>8$ patients per nurse & $10(32)$ & $3(23)$ & $2(18)$ & $5(71)$ & \\
\hline \multicolumn{6}{|l|}{ Work environment } \\
\hline Poor & $12(39)$ & $5(38)$ & $4(36)$ & $3(43)$ & \multirow[t]{3}{*}{0.330} \\
\hline Mixed & $8(26)$ & $4(31)$ & $1(9)$ & $3(43)$ & \\
\hline Better & $11(35)$ & $4(31)$ & $6(55)$ & $1(14)$ & \\
\hline
\end{tabular}

shown in table 4. The unadjusted ORs suggest that before taking account of other factors, a greater proportion of non-UK educated nurses had a significant and negative effect on whether patients rated their care as very good or excellent $(\mathrm{OR}=0.91)$, and a similarly significant and negative effect on three of the other six indicators of patient satisfaction. After taking account, in the adjusted models, of differences across the hospital trusts in both other hospital and patient characteristics, the effect of the proportion of non-UK educated nurses is even more pronounced, of roughly similar size for all seven outcome measures (ORs range from 0.86 to 0.93 ),

Table 4 Association between the proportion of non-UK educated nurses in hospital trusts and patient satisfaction

\begin{tabular}{|c|c|c|}
\hline \multirow[b]{2}{*}{ Outcome } & \multicolumn{2}{|c|}{ ORs† (95\% Cl) } \\
\hline & Unadjusted & Adjusted‡ \\
\hline Rate care received as very good or excellent & $\begin{array}{l}0.91^{*} \\
(0.83-0.99)\end{array}$ & $\begin{array}{l}0.88^{\star * *} \\
(0.83-0.93)\end{array}$ \\
\hline Did not want to complain about care & $\begin{array}{l}0.94 \\
(0.84-1.04)\end{array}$ & $\begin{array}{l}0.93 \\
(0.84-1.03)\end{array}$ \\
\hline Always treated with respect and dignity while in the hospital & $\begin{array}{l}0.94 \\
(0.87-1.00)\end{array}$ & $\begin{array}{l}0.92^{\star \star *} \\
(0.88-0.96)\end{array}$ \\
\hline A member of staff always explained the purpose of medicines & $\begin{array}{l}0.93^{*} \\
(0.86-0.99)\end{array}$ & $\begin{array}{l}0.90^{\star \star *} \\
(0.86-0.94)\end{array}$ \\
\hline Nurses always provide easy to understand answers & $\begin{array}{l}0.87^{\star \star \star} \\
(0.82-0.92)\end{array}$ & $\begin{array}{l}0.86^{\star \star *} \\
(0.82-0.90)\end{array}$ \\
\hline Always have confidence and trust in nurses & $\begin{array}{l}0.87^{\star \star \star} \\
(0.83-0.91)\end{array}$ & $\begin{array}{l}0.87^{\star * *} \\
(0.84-0.91)\end{array}$ \\
\hline There were always enough nurses on duty to care for the patient in the hospital & $\begin{array}{l}0.95 \\
(0.88-1.03)\end{array}$ & $\begin{array}{l}0.93^{*} \\
(0.88-0.99) \\
\end{array}$ \\
\hline
\end{tabular}

TORs refer to the change in the odds of the different outcomes associated with each $10 \%$ increase in the proportion of non-UK educated nurses in the hospital trusts. Single, double and triple asterisks denote ORs that are significant at the $0.05,0.01$ and 0.001 levels, respectively.

$\ddagger$ The adjusted model included controls for patient characteristics (gender, age, limiting long-term condition, type of admission (emergency or planned), length of stay, discharge ward) and hospital/trust characteristics (size, technology status, nurse staffing (day nurse) and the practice environment). 
and statistically significant for six of the seven. These ORs imply, for example, that patients in a hospital with $10 \%$ non-UK educated nurses would be less likely by a factor of 0.88 (or $12 \%$ less likely) than patients in hospitals with no non-UK educated nurses to rate their care as very good or excellent. Patients in a hospital with $30 \%$ non-UK educated nurses would be less likely by a factor of $0.88^{3}=0.68$ (or $32 \%$ less likely) than patients in hospitals with no non-UK educated nurses to rate their care as very good or excellent.

\section{DISCUSSION}

\section{Summary of main results}

This study provides the first empirical evidence that employment of high proportions of non-UK educated nurses by NHS hospitals is associated with lower patient satisfaction with care. We found that even after taking account of differences in trusts in nurse staffing, the quality of the nurse work environment, and other features of the trusts including location, every $10 \%$ increase in the proportion of non-UK educated nurses was associated with a $12 \%$ decrease in the likelihood of patients rating the hospital good or excellent (as opposed to fair or poor) and a similar decrease in the likelihood of patients 'always' having confidence and trust in nurses.

The lower patient satisfaction reported by patients cared for in hospitals that employed substantial proportions of non-UK educated nurses could not be explained by other features of these hospitals. For example, lower satisfaction was not explained by poorer nurse staffing or poorer work environments of hospitals that employed substantial numbers of non-UK nurses. Neither was the lower observed patient satisfaction in hospitals employing substantial numbers of non-UK educated nurses explained by the location of hospitals or other features of hospitals such as size, high technology, or teaching status, or by the characteristics of the patients providing ratings.

Our findings suggest that there is an important link between substantial numbers of nurses trained abroad and lower patient satisfaction. These findings have important implications for national nurse workforce planning, especially in the current context where there are substantially more UK applicants to nursing schools than funded student positions. ${ }^{11}$ The long-standing UK policy of turning to international nurse recruitment rather than investing adequately in the domestic supply of nurses may have negative consequences for quality of care, as measured by patient satisfaction, while at the same time limiting opportunities for UK citizens to become nurses and thus benefit from the availability of good jobs.

\section{Discussion of differences in outcomes}

The link between lower patient satisfaction and nursing education outside the UK is not well understood. Language and cultural differences may play a role in the association between higher proportions of non-UK nurses and lower patient satisfaction. The majority of hospitalised patients surveyed were 66 years of age or older, and acutely ill older patients may have hearing and communications challenges. Also, transcultural research suggests that professional nursing practice may be influenced by professional norms in the country of origin that are different from professional nursing expectations in an adopted country in ways that could influence quality of care and patient satisfaction, including nurse physician communication. ${ }^{29}{ }^{30}$ Indeed, other findings from the RN4CAST study show that nurses educated in developing countries now practising in European hospitals are significantly more likely than European educated nurses to invest time in performing tasks that do not require the knowledge and skill of a professional nurse, such as cleaning patient rooms and equipment, ${ }^{31}$ while needed nursing care is left undone because of lack of time. The kinds of needed professional nursing care most frequently left undone in hospitals include spending time talking with patients and their families, and educating patients about their selfcare after discharge, activities that might be particularly salient to patients and influence their perceptions of their overall hospital experience. ${ }^{32}$

Large hospitals and those in London are particularly likely to employ larger proportions of non-UK educated nurses. In many cases, these are hospitals known for high quality of care and in general have good resources; thus, it is even more notable that despite good resources, patient satisfaction is lower than expected, seemingly related to high proportions of non-UK educated nurses. The number of student places commissioned in London has declined more than in other parts of the country, ${ }^{11}$ calling into question the effectiveness of devolving decision-making on nurse supply to the local trust level. Additionally, the very high cost of reasonable quality housing in London may discourage UK educated nurses from working in London hospitals. ${ }^{33}$ Trusts have the flexibility to adjust nationally determined nurse wage rates to account for high local costs of living, but there is little evidence that trusts fully exploit this opportunity to improve recruitment of UK educated nurses, potentially because of constrained budgets.

Historic patterns of nurse migration to England from English speaking Commonwealth countries to the south, as well as previously low nurse migration among Western European countries, are demonstrated in the primary countries of origins of the foreign educated nurses in the study. ${ }^{34}$ The inclusion of more Eastern European countries in the EU and the economic downturn with its austerity spending constraints are resulting in more nurse migration within Europe. Other than Ireland, much of the new EU nurse migration interest is from countries where English is not the primary spoken language and where healthcare is significantly different from England. Hence, the associations we find in this study may likely persist even if more migration to England is from EU countries. 


\section{Limitations}

The study uses cross-sectional data which cannot establish causality. Despite patient-level risk adjustment and use of multiple trust characteristics to control for potential confounds, we cannot rule out the possibility that variables omitted from our models may be responsible for the associations found. While our study is limited to 31 of the 160 acute NHS trusts in England, participating trusts were obtained through a stratified, random sampling procedure, and the participating hospitals as a group are not significantly different in characteristics from other trusts of more than 100 beds nationally. Moreover our results are robust even without controls for institutional characteristics suggesting that unique features of the participating hospitals are not responsible for the observed association between higher proportion of non-UK educated nurses and lower patient satisfaction. Our data are from 2010, which is the latest data available on the variables studied, but there is little reason to anticipate that the relationship between non-UK nurses and patient satisfaction has fundamentally changed in the intervening years.

\section{CONCLUSIONS}

Utilisation of a substantial proportion of non-UK educated nurses in English NHS hospitals is associated with lower patient satisfaction with the overall hospital experience, and with lower satisfaction with nursing care specifically. Recent estimates show that 1 in 10 nurses in the UK is from another country. ${ }^{13}$ Diversity in the nurse workforce is an important goal, but one that could be achieved by making nursing education more accessible to UK citizens. Our findings suggest that the use of nurses educated in other countries to substitute for professional nurses educated at home is not without risks to quality of care.

Twitter Follow Hayley Germack at @hgermack Jane Ball at @JaneEBall and Linda Aiken @LindaAiken_Penn

Contributors HDG wrote the analysis plan, cleaned and analysed the data, and drafted and revised the paper. LHA supported the interpretation of results, drafted and revised the paper. DMS, PG, AMR and JEB supported the interpretation of results and revised the paper.

Funding This research was funded by the European Union's Seventh Framework Programme (FP7/2007-2013, grant agreement no 223468, W Sermeus, PI) the National Institute of Nursing Research (T32NR00714 and R01NR014855, LH Aiken, PI), and the Rita and Alex Hillman Foundation Scholars in Nursing Innovation.

Ethics approval The research protocol was approved by Kings College London and the University of Pennsylvania ethics committees.

Competing interests None declared.

Provenance and peer review Not commissioned; externally peer reviewed.

Data sharing statement No additional data are available.

Open Access This is an Open Access article distributed in accordance with the Creative Commons Attribution Non Commercial (CC BY-NC 4.0) license, which permits others to distribute, remix, adapt, build upon this work noncommercially, and license their derivative works on different terms, provided the original work is properly cited and the use is non-commercial. See: http:// creativecommons.org/licenses/by-nc/4.0/

\section{REFERENCES}

1. World Health Organization. The World Health Report 2000. Health systems: improving performance. Geneva: World Health Organization, 2000

2. Institute of Medicine. Crossing the quality chasm: a new health system for the 21st century. Washington DC: National Academy Press, 2001.

3. Coulter A, Jenkinson C. European patients' views on the responsiveness of health systems and healthcare providers. Eur J Public Health 2005;15:355-60.

4. NHS Surveys. Improving healthcare. Secondary improving healthcare, 2015. http://www.nhssurveys.org/improvinghealthcare (accessed 25 Oct 2015).

5. Francis R. Report of the Mid Staffordshire NHS Foundation Trust Public Inquiry. Secondary report of the Mid Staffordshire NHS Foundation Trust Public Inquiry, 2013. http://www. midstaffspublicinquiry.com/report (accessed 9 Sep 2015)

6. Keogh K. Review into the quality of care and treatment provided by 14 hospital trusts in England: overview report. Secondary review into the quality of care and treatment provided by 14 hospital trusts in England: overview report 2013. http://www.nhs.uk/nhsengland/ bruce-keogh-review/documents/outcomes/keogh-review-final-report. pdf (accessed 24 Jun 2015).

7. Aiken L, Rafferty A, Sermeus W. Caring nurses hit by a quality storm. Nurs Stand 2014;28:22-5.

8. Aiken L, Sloane D, Bruyneel L, et al. Nurse staffing and education and hospital mortality in nine European countries: a retrospective observational study. Lancet 2014;383:1824-30.

9. Buchan J. International recruitment of nurses: policy and practice in the United Kingdom. Health Serv Res 2007;42(3 Pt 2):1321-35.

10. Attree $\mathrm{M}$, Flinkman $\mathrm{M}$, Howley $\mathrm{B}$, et al. A review of nursing workforce policies in five European countries: Denmark, Finland, Ireland, Portugal and United Kingdom/England. J Nurs Manag 2011;19:786-802.

11. Buchan J, Seccombe I, O'May F. Safe staffing levels-a nationa imperative. The UK nursing labour market review 2013. London Royal College of Nursing, 2013.

12. Kingma M. Nurses on the move: migration and the global health care economy. Ithaca, NY: IRL Press, 2006.

13. Keogh $\mathrm{K}$. Overseas recruitment big business again as safe staffing recognised. Nurs Stand 2014;28:14-15

14. Neff DF, Cimiotti J, Sloane DM, et al. Utilization of non-US educated nurses in US hospitals: implications for hospital mortality. Int J Qual Health Care 2013;25:366-72.

15. Kutney-Lee A, McHugh MD, Sloane DM, et al. Nursing: a key to patient satisfaction. Health Aff 2009;28:w669-77.

16. Jha A, Orav E, Zheng J, et al. Patients' perception of hospital care in the United States. N Engl J Med 2008;359:1921-31.

17. Aiken LH, Sermeus W, Van den Heede K, et al. Patient safety, satisfaction, and quality of hospital care: cross sectional surveys of nurses and patients in 12 countries in Europe and the United States. BMJ 2012;344:e1717.

18. Picker Institute Europe. Guidance manual for the NHS adult inpatient survey 2009. Oxford: The Co-ordination Centre for the Acute Survey Programme, 2009

19. Sermeus W, Aiken LH, Van den Heede K, et al. Nurse forecasting in Europe (RN4CAST): rationale, design and methodology. BMC Nurs 2011;10:6

20. Smith HL. A double sample to minimize bias due to nonresponse in a mail survey. Population Studies Center Working Papers, 2009; (No. 09-05. 2009). http://repository.upenn.edu/cgi/ viewcontent.cgi $?$ article $=1013 \&$ context $=$ psc_working_papers (accessed 3 Aug 2015).

21. Lake ET. Development of the Practice Environment Scale of the Nursing Work Index. Res Nurs Health 2002;25:176-88.

22. Lake ET. The nursing practice environment: measurement and evidence. Med Care Res Rev 2007;64(2 Suppl):104S-22S

23. Aiken LH, Cimiotti JP, Sloane DM, et al. Effects of nurse staffing and nurse education on patient deaths in hospitals with different nurse work environments. Med Care 2011;49:1047-53.

24. Warshawsky NE, Havens DS. Global use of the Practice Environment Scale of the Nursing Work Index. Nurs Res 2011;60:17-31.

25. National Quality Forum. Practice Environment Scale-Nursing Work Index (PES-NWI) (composite and five subscales). Secondary Practice Environment Scale-Nursing Work Index (PES-NWI) (composite and five subscales), 2012. http://www.qualityforum.org (accessed 21 May 2013).

26. National Quality Forum. A consensus report: national voluntary consensus standards for nursing-sensitive care: an initial performance measure set. Secondary A consensus report: national voluntary consensus standards for nursing-sensitive care: an initial performance measure set. 2004. http://www.qualityforum.org/ 
Publications/2004/10/National_Voluntary_Consensus_Standards for_Nursing-Sensitive_Care_An_Initial_Performance_Measure_Set. aspx (accessed 5 Dec 2012).

27. Aiken LH, Clarke SP, Sloane DM, et al. Hospital nurse staffing and patient mortality, nurse burnout, and job dissatisfaction. JAMA 2002;288:1987-93.

28. StataCorp. 2014. Statistical Software: Release 13.1. College Station, TX: Stata Corporation.

29. Flynn L, Aiken LH. Does international nurse recruitment influence practice values in U.S. hospitals? J Nurs Scholarsh 2002;34:67-73.

30. Nichols B, Campbell J. The experiences of internationally recruited nurses in the UK (1995-2007): an integrative review. J Clin Nurs 2010;19:2814-23.
31. Bruyneel L, Li B, Aiken L, et al. A multi-country perspective on nurses' tasks below their skill level: reports from domestically trained nurses and foreign trained nurses from developing countries. Int $J$ Nurs Stud 2013;50:202-9.

32. Ball J, Murrells T, Rafferty A, et al. 'Care left undone' during nursing shifts: associations with workload and perceived quality of care. BMJ Qual Saf 2014;23:116-25.

33. Osborne $\mathrm{H}$. House prices: eight in 10 homes out of reach of families on average wages. The Guardian 2014 Jun 25. http://www. theguardian.com/money/2014/jun/25/house-prices-out-reach-shelterhousing-crisis

34. Aiken LH, Buchan J, Sochalski J, et al. Trends in international nurse migration. Health Aff 2004;23:69-77. 